\title{
Polymerization Initiated by Particle Contact: A Quiescent State Trigger for Materials Synthesis
}

\author{
Kristin M. Hutchins, ${ }^{\dagger, \ddagger}$ Nina M. Sekerak, ${ }^{\dagger}$ and Jeffrey S. Moore ${ }^{*,+, \ddagger}$ \\ ${ }^{\dagger}$ Department of Chemistry, University of Illinois at Urbana-Champaign, Urbana, IL \\ 61801, USA. \\ ${ }^{\ddagger}$ Beckman Institute of Advanced Science and Technology, University of Illinois at \\ Urbana-Champaign, Urbana, IL 61801, USA. \\ E-mail: jsmoore@illinois.edu
}

\section{Table of Contents}

I. General experimental details

II. Synthetic procedures

III. ${ }^{1} \mathrm{H}$ and ${ }^{13} \mathrm{C}$ NMR spectra

IV. Infrared spectra of polymer beads

$V$. Surface functionalization of silicon wafers

VI. Contact-initiated polymerization test with beads and functionalized wafers

VII. Confocal Raman spectra of functionalized silicon wafers and beads

VIII. Contact-initiated polymerization test with functionalized beads

IX. Confocal Raman images and spectra of functionalized beads

$X$. SEM images of polymer beads

XI. Swelling studies with polymer beads 


\section{General experimental details}

All reagents were purchased from Sigma Aldrich or the denoted commercial supplier and used without further purification unless otherwise stated. Ethanol (EtOH) and tetrahydrofuran (THF) were purchased from Fisher Scientific. 4-vinylbenzoic acid stabilized with butylated hydroxytoluene (BHT) was purchased from TCl America. N,N-Carbonyldiimidazole (CDI) was purchased from AK Scientific, Inc. Anhydrous solvents were obtained from an anhydrous solvent delivery system (SDS) equipped with activated alumina columns. Water was obtained from a Millipore (Billerica, MA) MilliQ water purification system. An IKA 20 digital mechanical stirrer was used for the suspension polymerization. Stainless steel, 8 inch diameter sieves were purchased from Hogentogler \& Co. Inc (sizes: 1 mm, $710 \mu \mathrm{m}, 500 \mu \mathrm{m}, 355 \mu \mathrm{m}$ ).

${ }^{1} \mathrm{H}$ and ${ }^{13} \mathrm{C}$ NMR spectra were recorded on Varian Unity-400 or Unity-500 MHz spectrometers. ${ }^{13} \mathrm{C}$ NMR spectra were measured with a proton-decoupling pulse sequence. Gel-phase ${ }^{13} \mathrm{C}$ NMR experiments were conducted by swelling the particles in THF- $\mathrm{d}_{8}$ for several hours before acquiring the spectrum. Chemical shifts $(\delta)$ are reported in ppm from tetramethylsilane with the solvent resonance as the internal standard $\left({ }^{1} \mathrm{H}\left(\mathrm{CDCl}_{3}\right) \delta=7.26 \mathrm{ppm},{ }^{13} \mathrm{C}\left(\mathrm{CDCl}_{3}\right) \delta=77.16\right.$ ppm; $\left.{ }^{1} \mathrm{H}(\mathrm{THF}) \delta=1.72 \mathrm{ppm},{ }^{13} \mathrm{C}(\mathrm{THF}) \delta=25.31 \mathrm{ppm}\right)$. Coupling constants are reported in Hertz (Hz). FT-IR spectra were recorded on a Nicolet Nexus 670 spectrometer with the DRIFTS attachment. ESI-HRMS spectra were recorded on a Waters Q-TOF Ultima mass spectrometer. Scanning electron microscopy (SEM) images were acquired on a Philips XL30 ESEM-FEG or a Hitachi S4700 at $2 \mathrm{kV}$. The SEM samples were sputter coated with a Au/Pd alloy. Raman spectra were collected on a Horiba LabRAM HR 3D Raman spectroscopy imaging system using a $532 \mathrm{~nm}$ laser line as the excitation source. The Raman spectra of the wafers were normalized by setting the peak at ca $520 \mathrm{~cm}^{-1}$ (from silicon wafer) equal to 1 . Water contact angles were measured on a contact angle goniometer. Optical images were obtained using a Leica microscope. Stereo microscope images were obtained using a Carl Zeiss SteREO Discovery V20 microscope

\section{Synthetic procedures}

Synthesis of tert-butyl-4-vinylbenzoate (tBuVB)

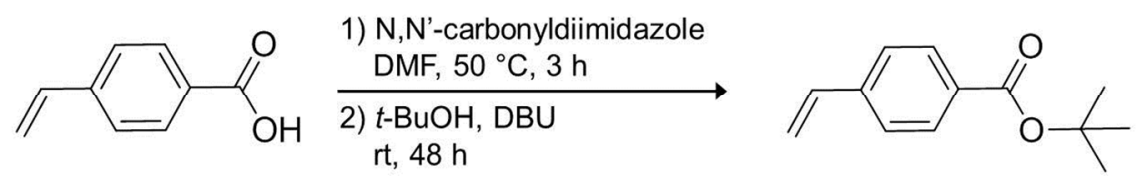

The protected vinyl monomer, tert-butyl-4-vinylbenzoate (tBuVB), was synthesized using a modified literature procedure. ${ }^{1}$ 4-vinylbenzoic acid $(6 \mathrm{~g}, 40.5 \mathrm{mmol})$ and N,N'carbonyldiimidazole $(10.0 \mathrm{~g}, 61.7 \mathrm{mmol})$ were dissolved in DMF $(18 \mathrm{~mL})$ and heated to $50{ }^{\circ} \mathrm{C}$ for $3 \mathrm{~h}$. The reaction mixture was removed from heat, and $\mathrm{tBuOH}(5.0 \mathrm{~mL}, 52 \mathrm{mmol})$ and 1,8diazabicyclo[5.4.0]undec-7-ene (DBU) $(2.4 \mathrm{~mL}, 16 \mathrm{mmol})$ were added by syringe. The mixture was stirred at room temperature for $48 \mathrm{~h}$. After $48 \mathrm{~h}$, the reaction mixture was diluted with 
diethyl ether $(300 \mathrm{~mL})$ and washed with $0.5 \mathrm{M} \mathrm{HCl}(3 \times 100 \mathrm{~mL})$ and saturated sodium carbonate $(2 \times 50 \mathrm{~mL})$. The organic layer was dried over magnesium sulfate. To the organic layer, butylated hydroxytoluene $(\mathrm{BHT})(8.0 \mathrm{mg}, 36 \mu \mathrm{mol})$ was added. The product was concentrated in vacuo to afford $5.7 \mathrm{~g}$ (73\% yield) of a light yellow oil, which was stored at -30 ${ }^{\circ} \mathrm{C}$.

${ }^{1} \mathrm{H}$ NMR $\left(\mathrm{CDCl}_{3}\right): \delta 7.94(\mathrm{~d}, 2 \mathrm{H}, J=8.3 \mathrm{~Hz}), 7.44(\mathrm{~d}, 2 \mathrm{H}, J=8.3 \mathrm{~Hz}), 6.75(\mathrm{dd}, 1 \mathrm{H}, J=17.6$, $10.9 \mathrm{~Hz}), 5.85(\mathrm{~d}, 1 \mathrm{H}, J=17.7 \mathrm{~Hz}), 5.36(\mathrm{~d}, 1 \mathrm{H}, J=10.9 \mathrm{~Hz}), 1.59(\mathrm{~s}, 9 \mathrm{H})$.

${ }^{13} \mathrm{C}-\mathrm{NMR}\left(\mathrm{CDCl}_{3}\right): \delta 165.53,141.38,136.09,131.13,129.67,125.90,116.09,80.92,28.18$.

Synthesis of protected carboxy-polystyrene (PS) beads

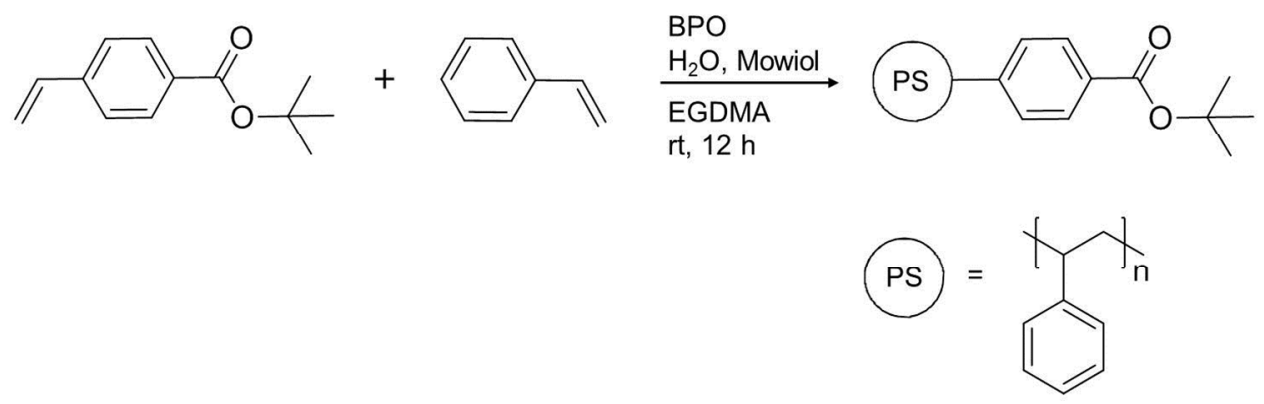

The inhibitors were removed from $t B u V B$ and styrene before polymerization by passage through basic alumina. In a 300-mL three-neck flask, Millipore water (110 g), Mowiol 40-88 (MW $\sim 205,000 \mathrm{~g} / \mathrm{mol}, 88 \%$ hydrolyzation, $0.25 \mathrm{~g}$ ), styrene $(16.1 \mathrm{~g}, 155 \mathrm{mmol})$, ethylene glycol dimethacrylate (EGDMA) $(0.11 \mathrm{~g}, 0.58 \mathrm{mmol}), t B u V B(2.0 \mathrm{~g}, 9.8 \mathrm{mmol})$, and benzoyl peroxide (BPO, Luperox, $0.50 \mathrm{~g}, 1.5 \mathrm{mmol}$ ) were stirred at $240 \mathrm{rpm}$ by an IKA 20 digital mechanical stirrer, purged with nitrogen for $15 \mathrm{~min}$, and heated to $70^{\circ} \mathrm{C}$. After $12 \mathrm{~h}$ of heating, the reaction mixture was cooled to room temperature. The particles were isolated by centrifugation for three minutes at $3000 \mathrm{rpm}$, washed five times in $\sim 3: 7$ THF/EtOH by redispersion and centrifugation for three minutes at $3000 \mathrm{rpm}$, and dried in vacuo to yield $11.9 \mathrm{~g}$ particles.

Cleavage of tert-butyl protecting group

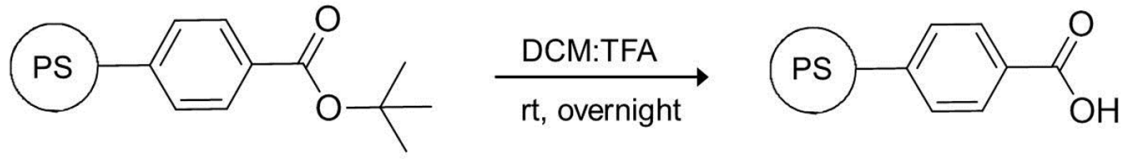

The protected carboxy-PS particles $(5.65 \mathrm{~g})$ were suspended in 1:1 DCM/trifluoroacetic acid $(v / v, 100 \mathrm{~mL}$ total) and the mixture was stirred at room temperature for $12 \mathrm{~h}$. DCM and trifluoroacetic acid were removed in vacuo. The carboxy-PS particles were washed five times in THF/EtOH by redispersion and centrifugation (same conditions as protected particles), and dried in vacuo to yield $4.3 \mathrm{~g}$ particles ( $80 \%$ yield). 
Functionalization of carboxy-PS beads with 3-chloroperbenzoic acid (BPO beads)

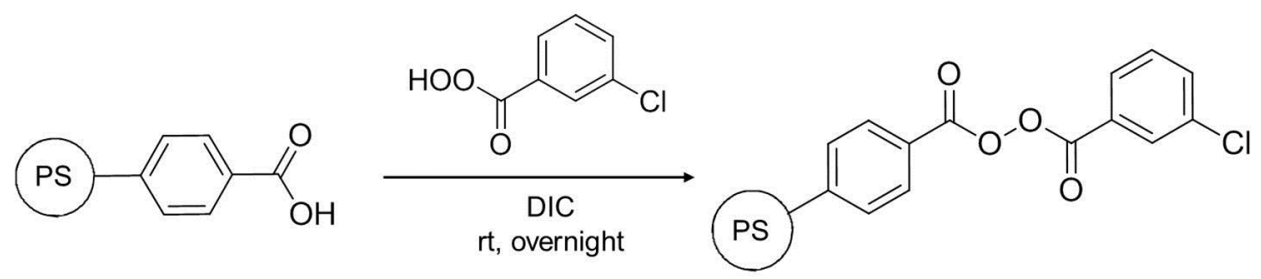

The carboxy-PS particles $(1.1 \mathrm{~g})$ were swollen in a solution of meta-chloroperoxybenzoic acid $(m C P B A)(0.98 \mathrm{~g}, 5.7 \mathrm{mmol})$ in DCM $(25 \mathrm{~mL})$. To this mixture, N,N'diisopropylcarbodiimide (DIC) $(0.55 \mathrm{~mL}, 3.6 \mathrm{mmol})$ was added. After $12 \mathrm{~h}, 25 \mathrm{~mL}$ EtOH was added to the reaction mixture. The particles were isolated by centrifugation, washed five times in THF/EtOH by redispersion and centrifugation (same conditions as protected particles), and dried in vacuo to yield $1.1 \mathrm{~g}(96 \%$ yield) of benzoyl peroxide (BPO)-functionalized particles. Peaks associated with the carboxylic acid group were not visible in the gel-phase ${ }^{13} \mathrm{C}$ NMR or DRIFTS spectra, indicating (within limits of detection) complete transformation to the desired functional group. Following functionalization, the polydisperse particles were subjected to a sieve shaker to yield relatively monodisperse particles.

Functionalization of carboxy-PS beads with 4-(dimethylamino)benzyl alcohol (DMA beads)

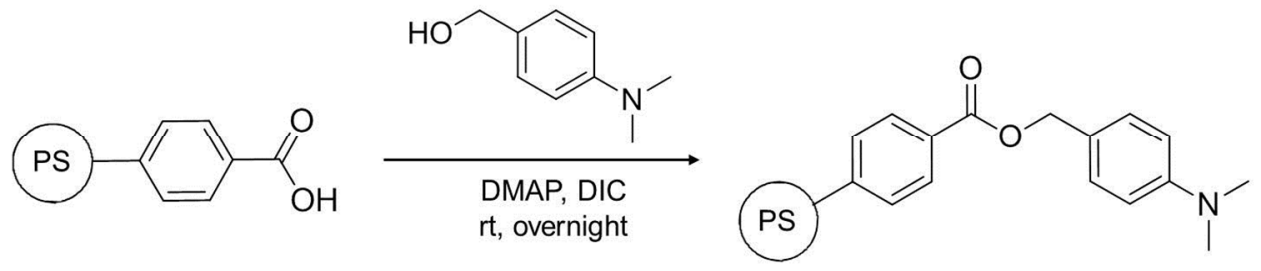

4-(dimethylamino)benzyl alcohol was synthesized by reduction of the corresponding aldehyde according to a literature procedure. ${ }^{2}$ The carboxy-PS particles $(1.1 \mathrm{~g})$ were swollen in a solution of 4-dimethylaminopyridine ( $0.34 \mathrm{~g}, 2.8 \mathrm{mmol}$ ) and 4-(dimethylamino)benzyl alcohol $(0.42 \mathrm{~g}, 2.8$ $\mathrm{mmol}$ ) in DCM (35 mL). To this mixture, N,N'diisopropylcarbodiimide (DIC) $(0.44 \mathrm{~mL}, 2.8 \mathrm{mmol})$ was added. After $12 \mathrm{~h}, 15 \mathrm{~mL}$ EtOH was added to the reaction mixture. The particles were isolated by centrifugation, washed five times in THF/EtOH by redispersion and centrifugation (same conditions as protected particles), and dried in vacuo to yield $0.63 \mathrm{~g}$ (66\% yield) of dimethylaniline (DMA) functionalized particles. Peaks associated with the carboxylic acid group were not visible in the gel-phase ${ }^{13} \mathrm{C}$ NMR or DRIFTS spectra, indicating (within limits of detection) complete transformation to the desired functional group. Following functionalization, the polydisperse particles were subjected to a sieve shaker to yield relatively monodisperse particles. 
III. ${ }^{1} \mathrm{H}$ and ${ }^{13} \mathrm{C}$ NMR spectra
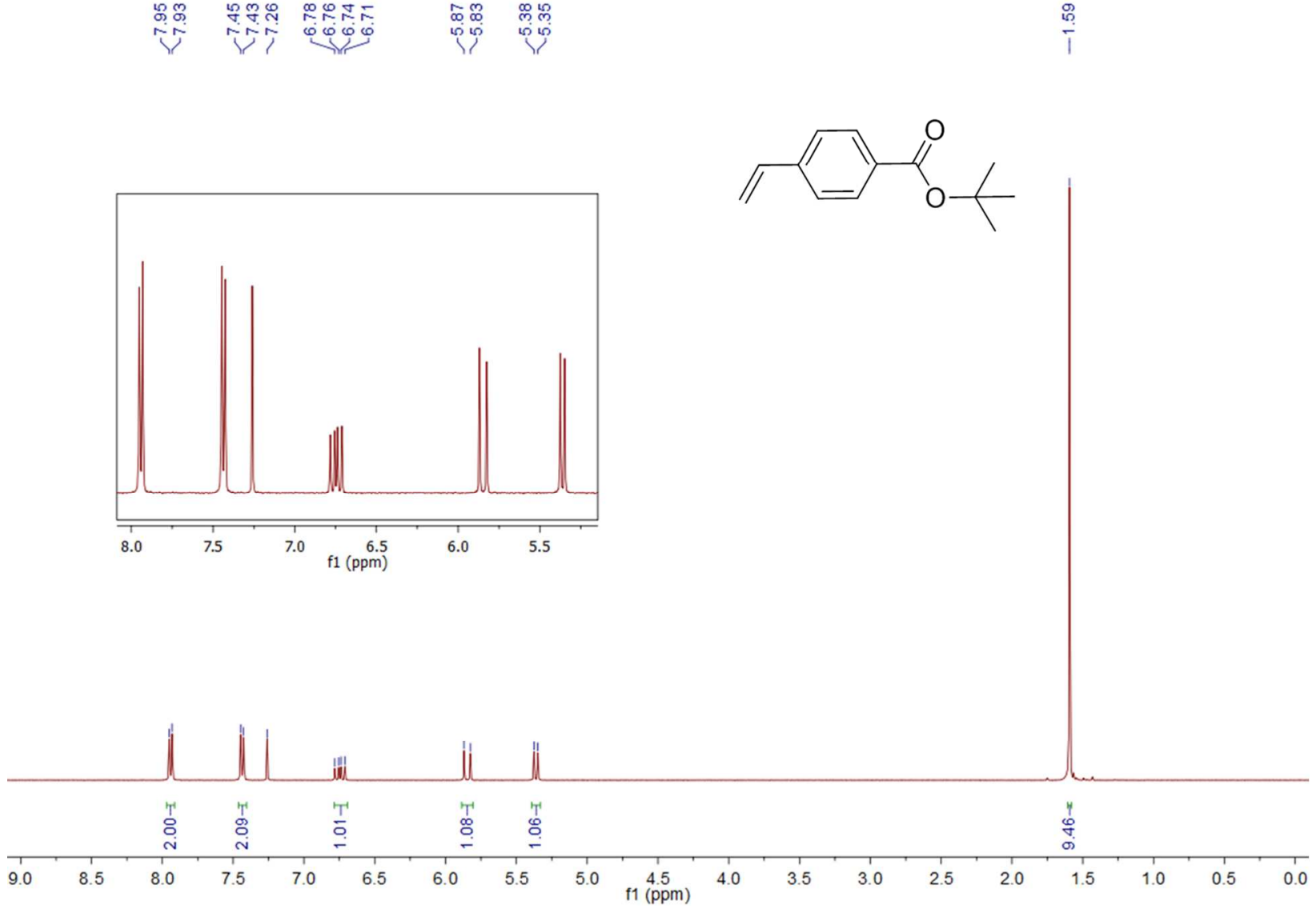

Figure S1. ${ }^{1} \mathrm{H}$ NMR spectrum of tert-butyl-4-vinylbenzoate (tBuVB).

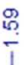

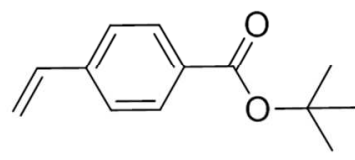




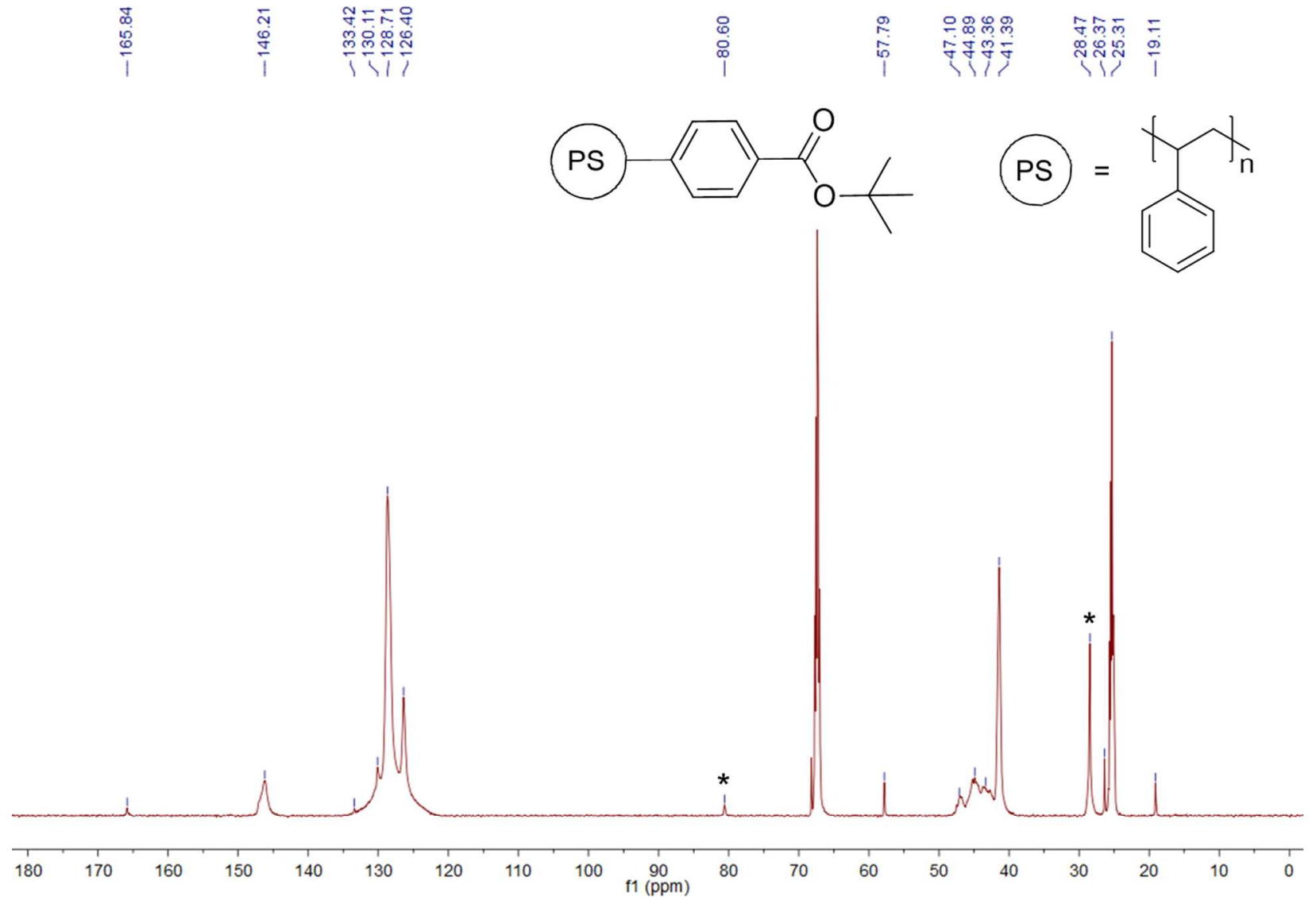

Figure S2. Gel-phase ${ }^{13} \mathrm{C}$ NMR spectrum of protected carboxy-PS beads in THF- $\mathrm{d}_{8}$. Peaks highlighted with asterisks correspond to the tert-butyl protecting group. 


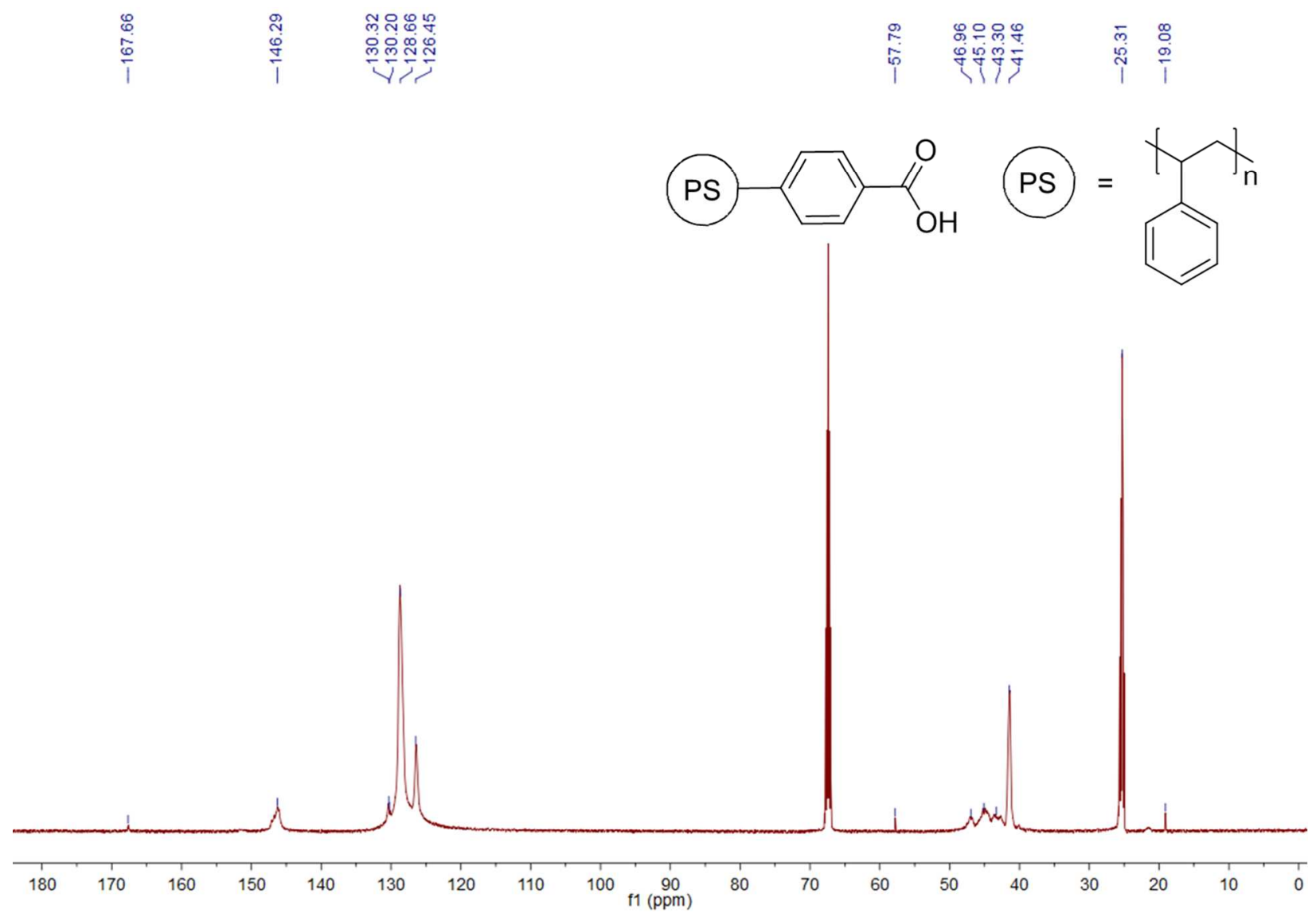

Figure S3. Gel-phase ${ }^{13} \mathrm{C}$ NMR spectrum of deprotected carboxy-PS beads in THF- $\mathrm{d}_{8}$. The tertbutyl peaks are absent in this spectrum. The carbonyl peak shifted from $\delta 165.8$ to $167.7 \mathrm{ppm}$ following deprotection. 


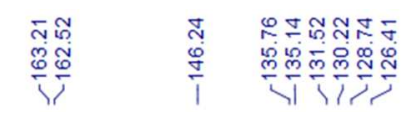

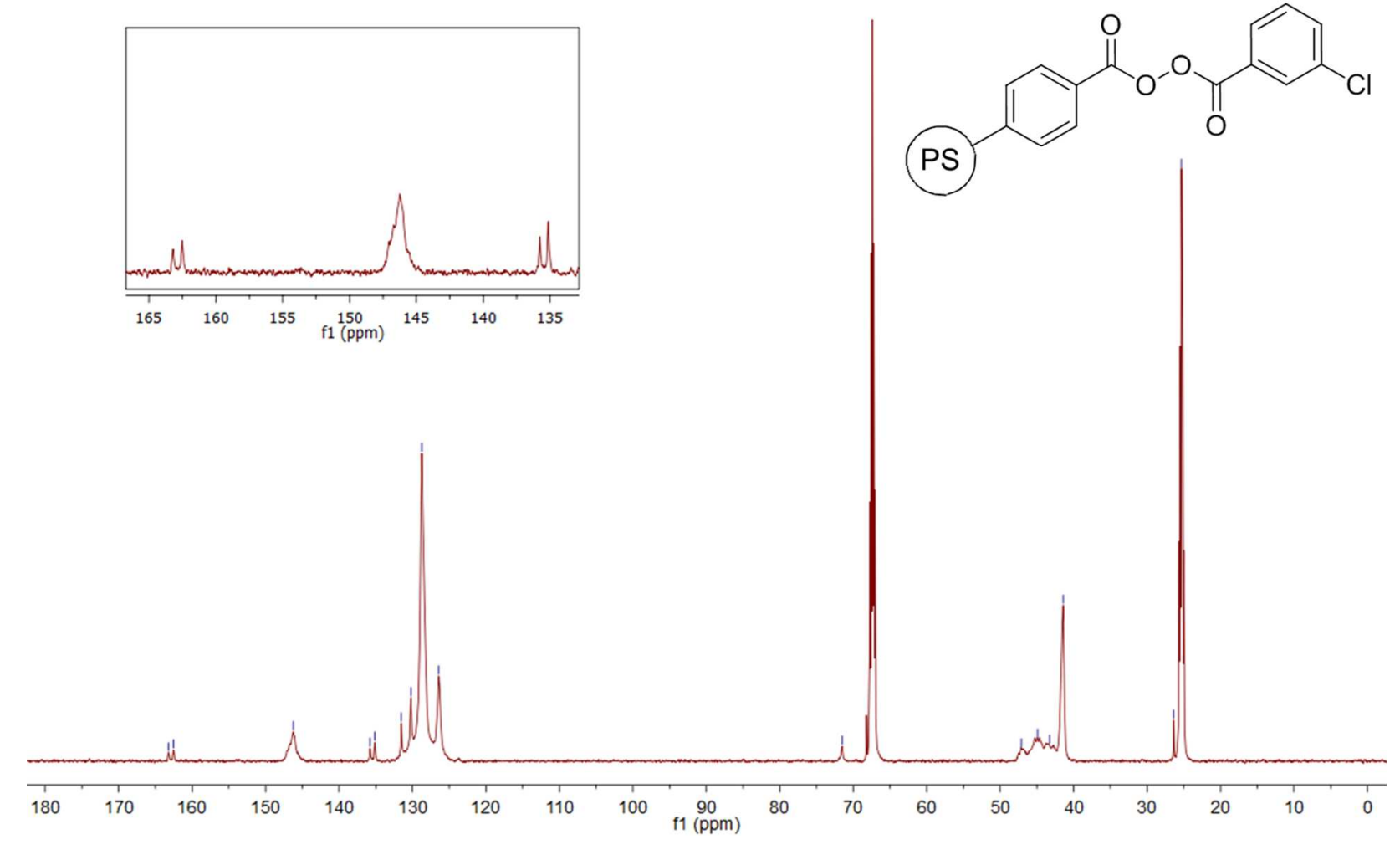
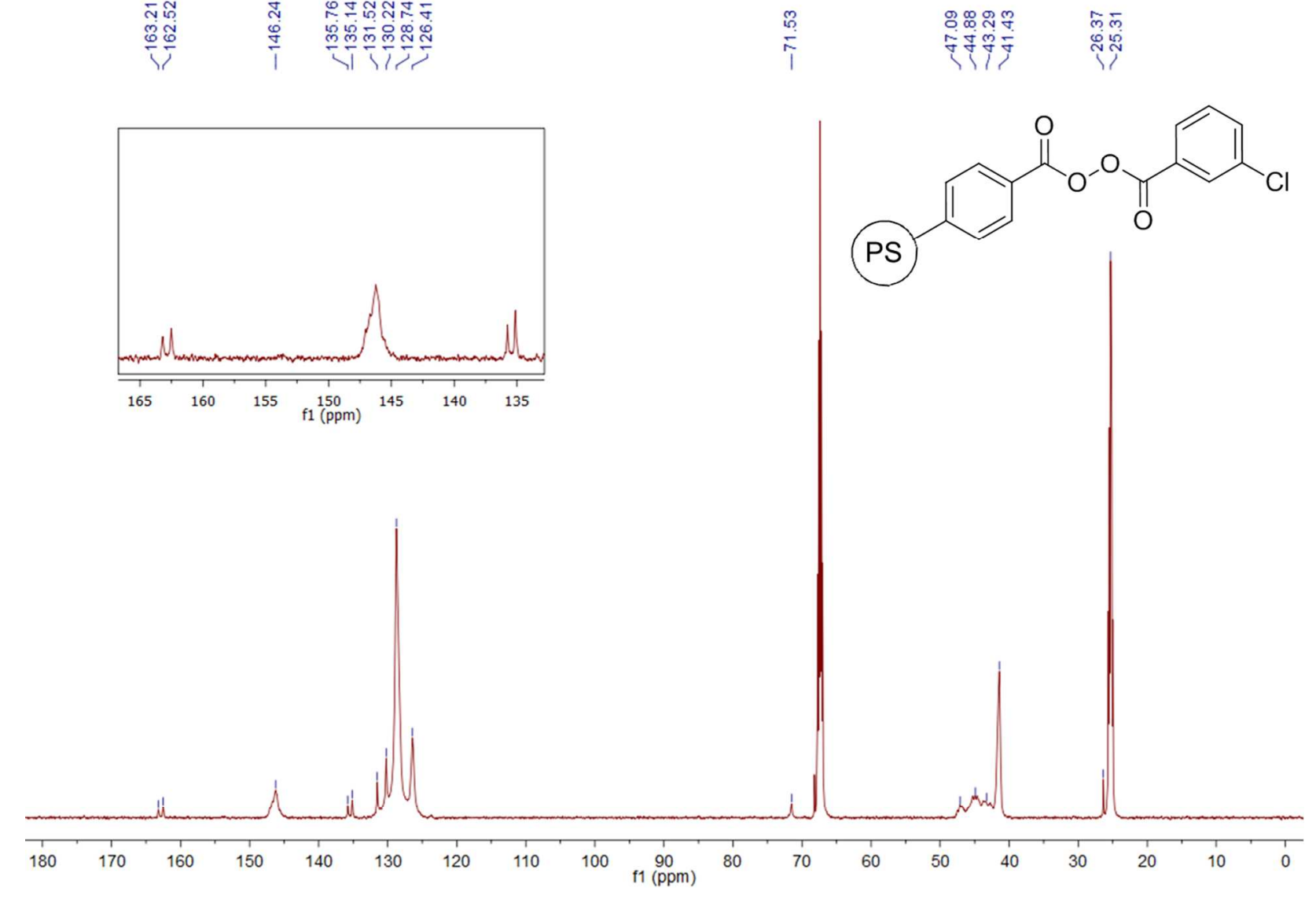

Figure S4. Gel-phase ${ }^{13} \mathrm{C}$ NMR spectrum of 3-chloroperbenzoic acid-functionalized carboxy-PS beads (BPO beads) in THF-d $\mathrm{d}_{8}$. Inset highlights new carbonyl and aromatic peaks. The two new peaks at $\delta 162.5$ and 163.2 ppm correspond to the carbonyl groups attached to the peroxide. 


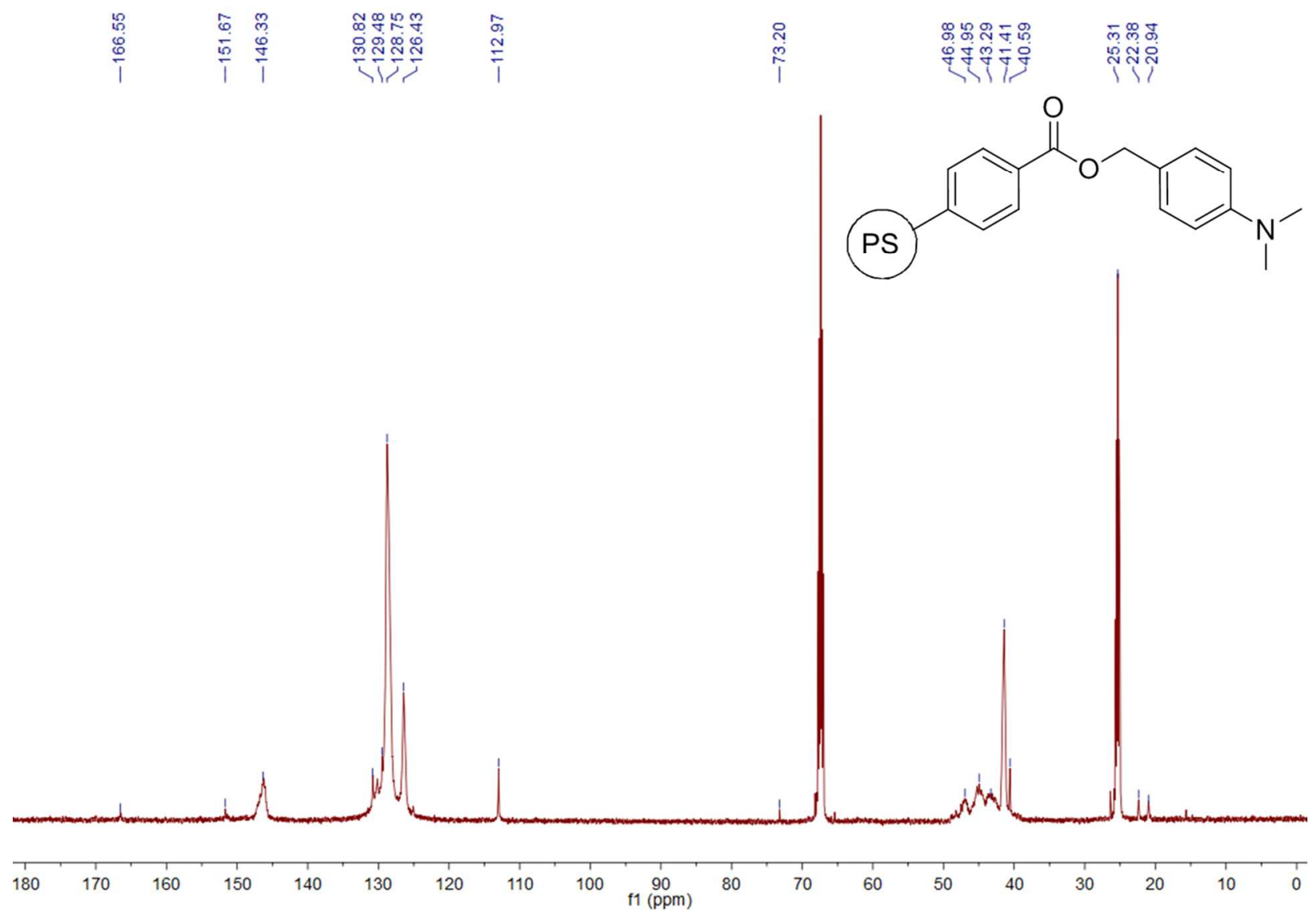

Figure S5. Gel-phase ${ }^{13} \mathrm{C}$ NMR spectrum of 4-(dimethylamino)benzyl alcohol-functionalized carboxy-PS beads (DMA beads) in THF-d 8 . 


\section{Infrared spectra of polymer beads}

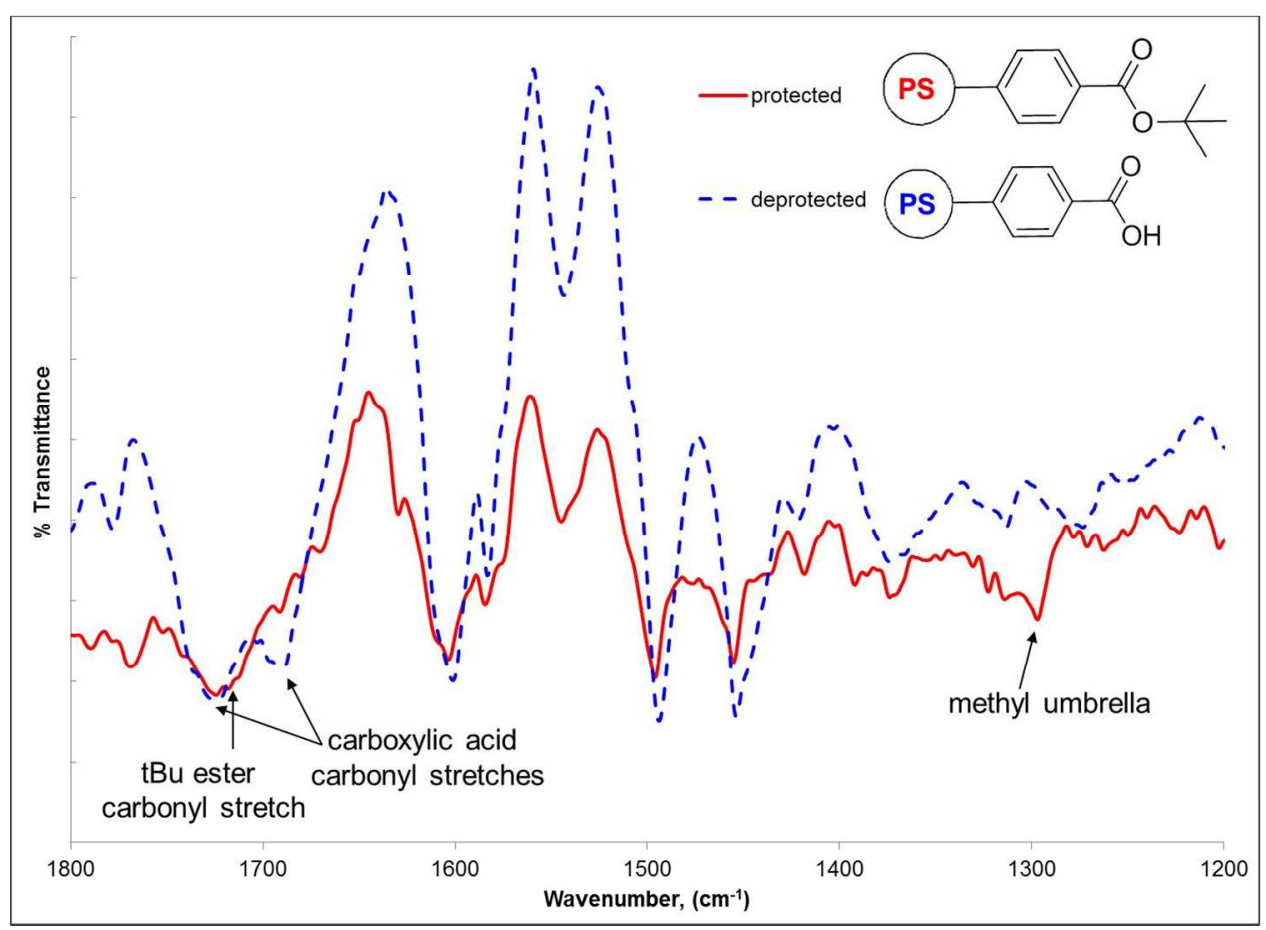

Figure S6. DRIFTS spectra of protected and deprotected carboxy-PS beads. The spectrum of the protected carboxy-PS beads exhibits one carbonyl stretch at $1724 \mathrm{~cm}^{-1}$ and a methyl umbrella bend at $1297 \mathrm{~cm}^{-1}$, while the deprotected carboxy-PS particles show two carbonyl stretches at 1727 and $1689 \mathrm{~cm}^{-1}$, corresponding to the free and dimerized carboxylic acid. 


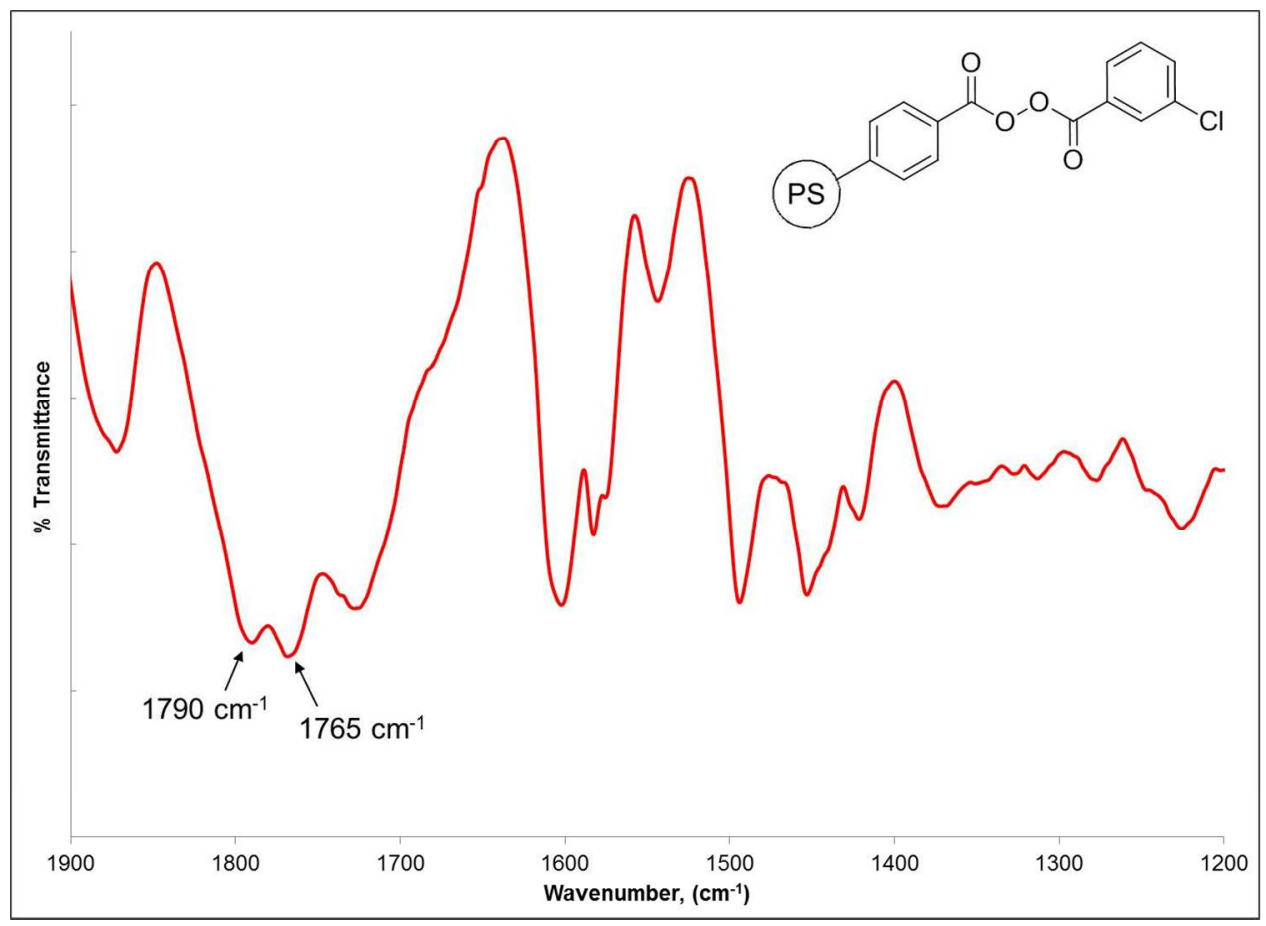

Figure S7. DRIFTS spectrum of BPO beads. Labeled peaks correspond to carbonyl stretches.

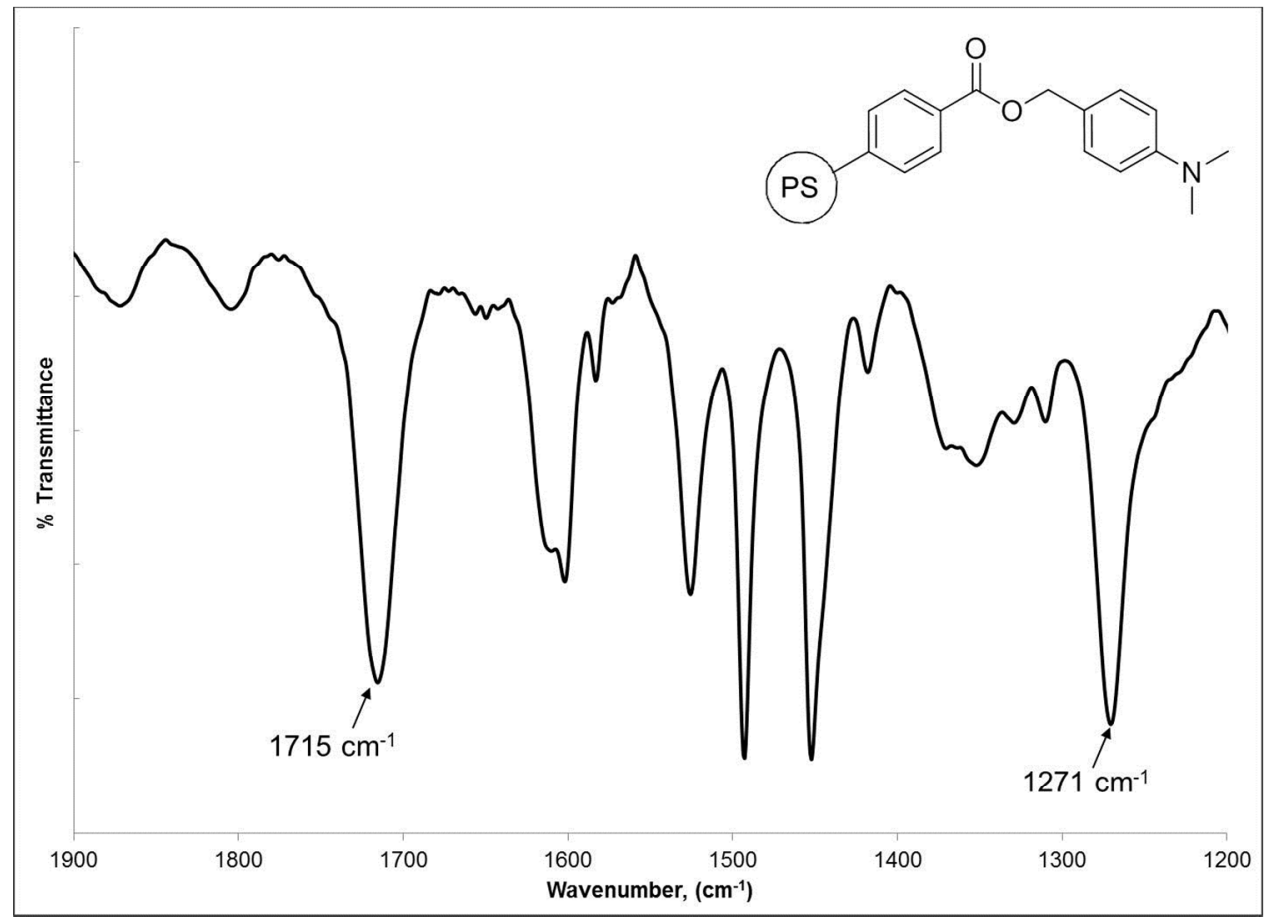

Figure S8. DRIFTS spectrum of DMA beads. Labeled peaks correspond to carbonyl and methyl stretches. 


\section{Surface functionalization of silicon wafers}

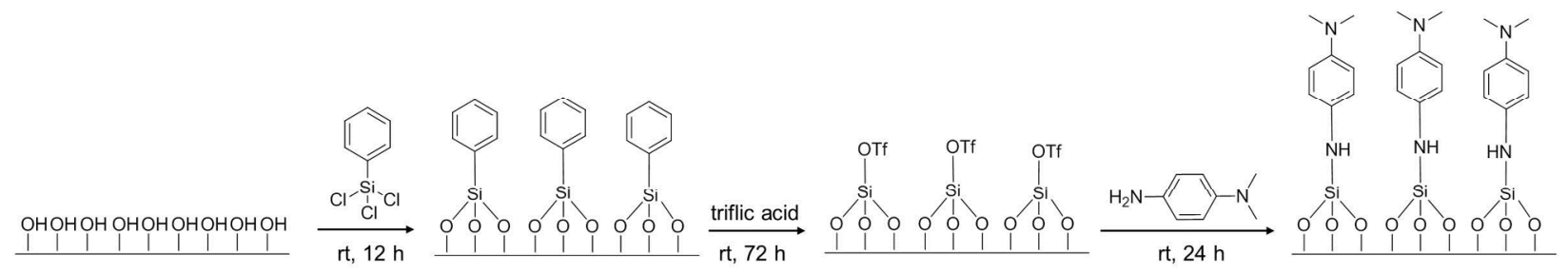

The silicon wafer surfaces were functionalized according to a literature procedure ${ }^{3}$ with the incorporation of $N, N$-dimethyl-p-phenylenediamine as the aniline. P-doped (100)-oriented silicon wafers (WRS materials) were cut into approximately $1 \mathrm{~cm} \times 1 \mathrm{~cm}$ squares. The wafers were cleaned before functionalization by sonicating in acetone to remove organic residue and dried in an oven at $100{ }^{\circ} \mathrm{C}$ for $20 \mathrm{~min}$. A hydroxylated silicon surface was formed by immersing the wafers in a piranha solution $\left(3: 1 \mathrm{v} / \mathrm{v} \mathrm{H}_{2} \mathrm{SO}_{4}: \mathrm{H}_{2} \mathrm{O}_{2}\right)$ for a period of $30 \mathrm{~min}$. The wafers were rinsed with DI water and dried under nitrogen. The average water contact angle on the surface was $22^{\circ}$ (five locations gave similar values).

The silicon wafers were functionalized by immersing them in a solution of phenyltrichlorosilane in dry toluene $(25 \mu \mathrm{L}$ in $25 \mathrm{~mL})$ for a period of $16 \mathrm{~h}$. After removal from the solution, the wafers were rinsed twice with dry toluene, sonicated in toluene for $1 \mathrm{~min}$, rinsed with acetone, rinsed with ethanol, and dried under nitrogen. The average water contact angle on the surface was $72^{\circ}$ (five locations gave similar values).

The dearylation of the phenyl group was carried out by immersing the wafers in a $99 \%$ triflic acid under nitrogen for a period of $72 \mathrm{~h}$. After removal from the solution, the wafers were rinsed twice with dry toluene, twice with dry hexanes, wiped gently with a hexanes-soaked tissue, and dried under nitrogen. The average water contact angle on the surface was $38^{\circ}$ (five locations gave similar values).

The nucleophilic substitution of the aniline was carried out by immersing the wafers in a saturated solution of $\mathrm{N}, \mathrm{N}$-dimethyl-p-phenylenediamine in toluene for a period of $24 \mathrm{~h}$. After removal from the solution, the wafers were rinsed with dry toluene, $\mathrm{N}$-methylpyrrolidinone (to remove unreacted aniline), methanol (to remove residual $\mathrm{N}$-methylpyrrolidinone), and dried under nitrogen. 


\section{Contact-initiated polymerization test with beads and functionalized wafers}

The inhibitor was removed from methyl acrylate (MA) before polymerization by passage through basic alumina. A DMA-functionalized silicon wafer was immersed in MA at room temperature under ambient atmosphere. Approximately $10 \mathrm{mg}$ of BPO-functionalized beads were placed on the surface. A glass stopper was placed on top of the particles on the surface for a period of 90 minutes. The setup was covered with a beaker and aluminum foil. The stopper was removed and the beads remaining on the surface were rinsed with Milli-Q water and methanol to remove unreacted MA monomer, then peeled from the surface with tweezers. The wafer was gently rinsed with Milli-Q water, rinsed with methanol, and wiped gently with a methanol-soaked Kimwipe. Confocal Raman spectra and optical images of the silicon wafers were collected.

Two control experiments were conducted by repeating the above procedure with: 1) a piranhacleaned silicon wafer and BPO-functionalized beads and 2) a DMA-functionalized wafer and deprotected (non-functionalized) carboxy-PS beads.

We note that shorter reaction times $(5,10,30$, and $60 \mathrm{~min}$ ) did result in polymerization (as evidenced by confocal Raman microscopy); however, the outlines of the beads were not as clearly observable. Reactions utilizing fewer BPO beads (ca $50 \%$ surface coverage) also resulted in successful polymerization and bead adhesion to the surface; however, close-packing arrangements of beads were not as clearly observed.
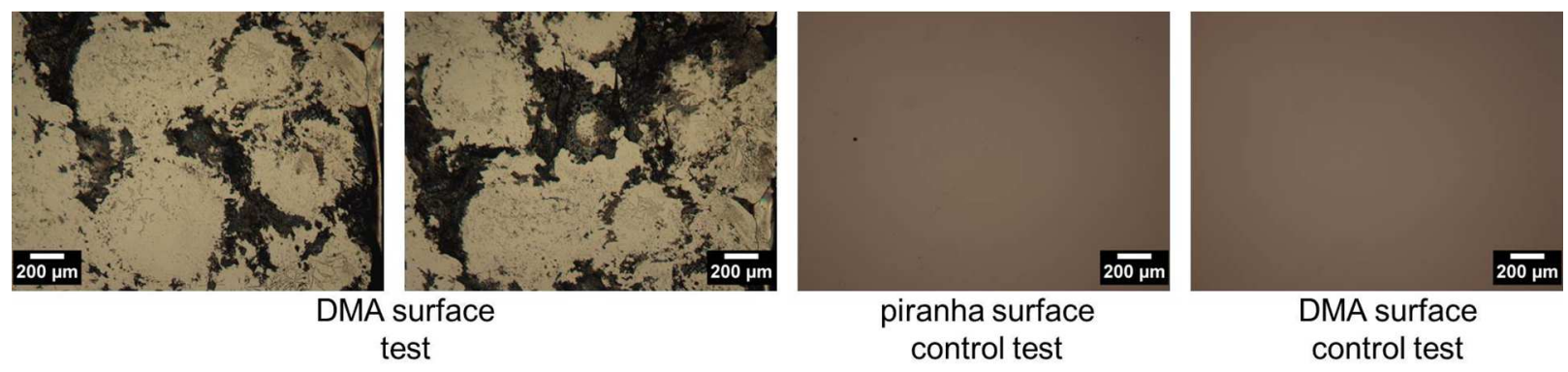

Figure S9. Optical images of: (DMA surface test) DMA surface + BPO beads + MA for 90 min at rt, (piranha surface control test) piranha-cleaned surface + BPO beads + MA for 90 min at rt, and (DMA surface control test) DMA surface + carboxy-PS beads + MA for 90 min at rt. 


\section{Confocal Raman spectra of functionalized silicon wafers and beads}

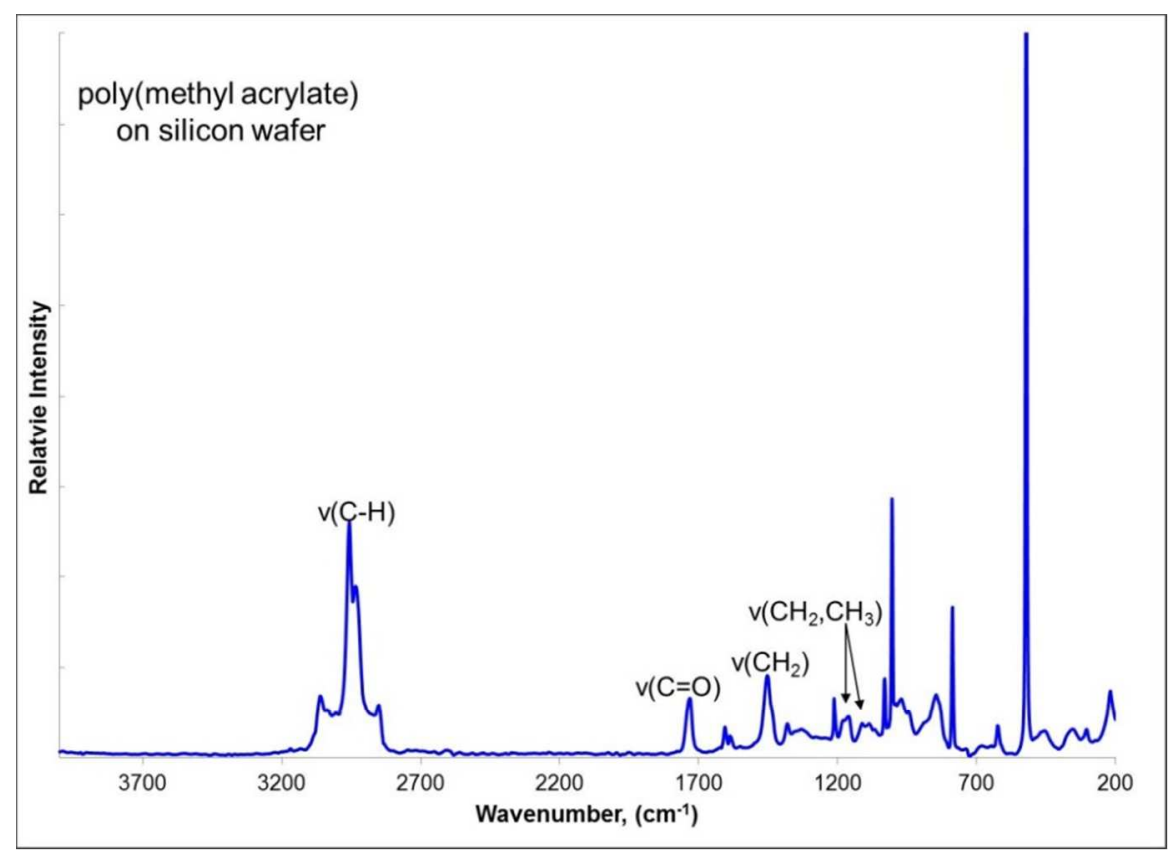

Figure S10. Raman spectrum of commercial poly(methyl acrylate) (PMA) deposited on a silicon wafer.

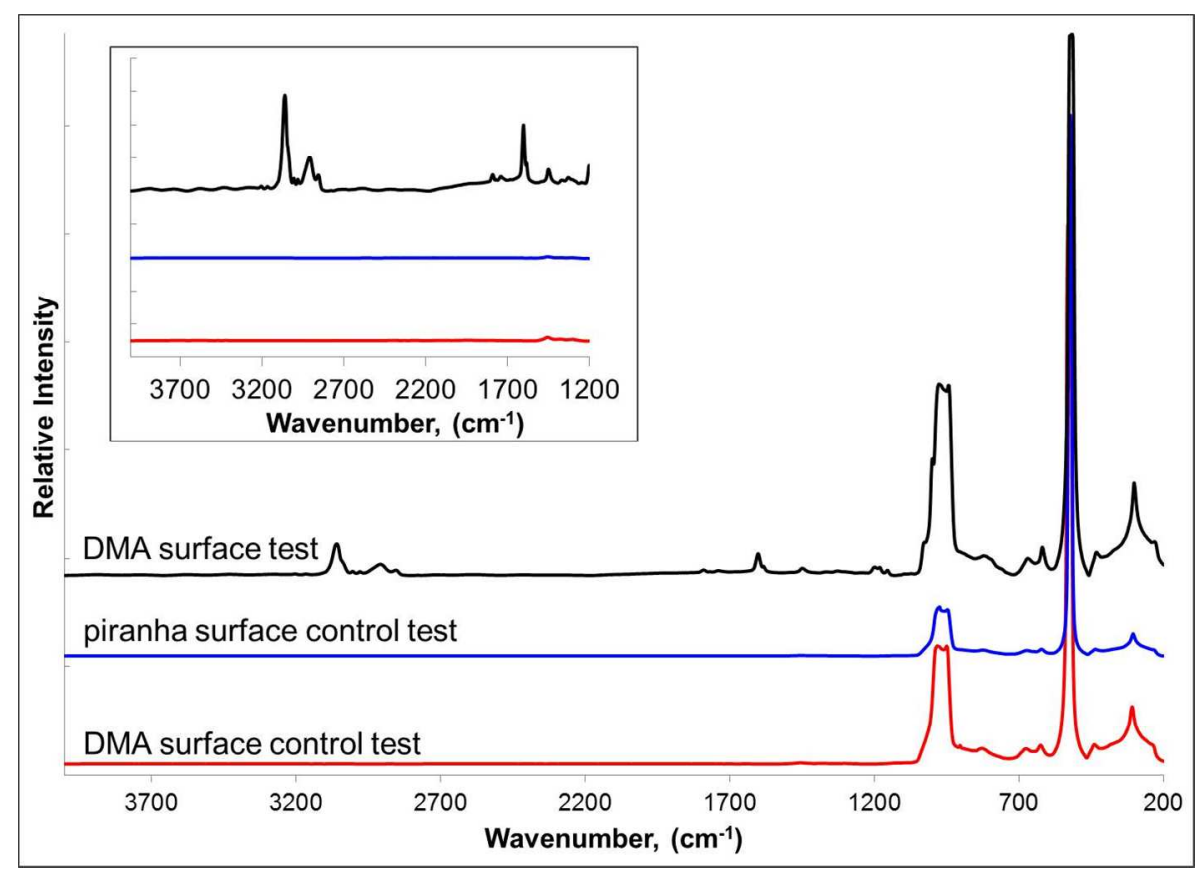

Figure S11. Raman spectra of silicon wafers following contact tests with beads: DMAfunctionalized after deprotected carboxy-PS (non-functionalized) bead contact test (control), piranha-cleaned after BPO bead contact test (control), and DMA-functionalized after BPO bead contact test. Inset highlighting region from $1200-4000 \mathrm{~cm}^{-1}$. Signals from PMA are in good agreement with those from the PMA spectrum in Fig. S10. 


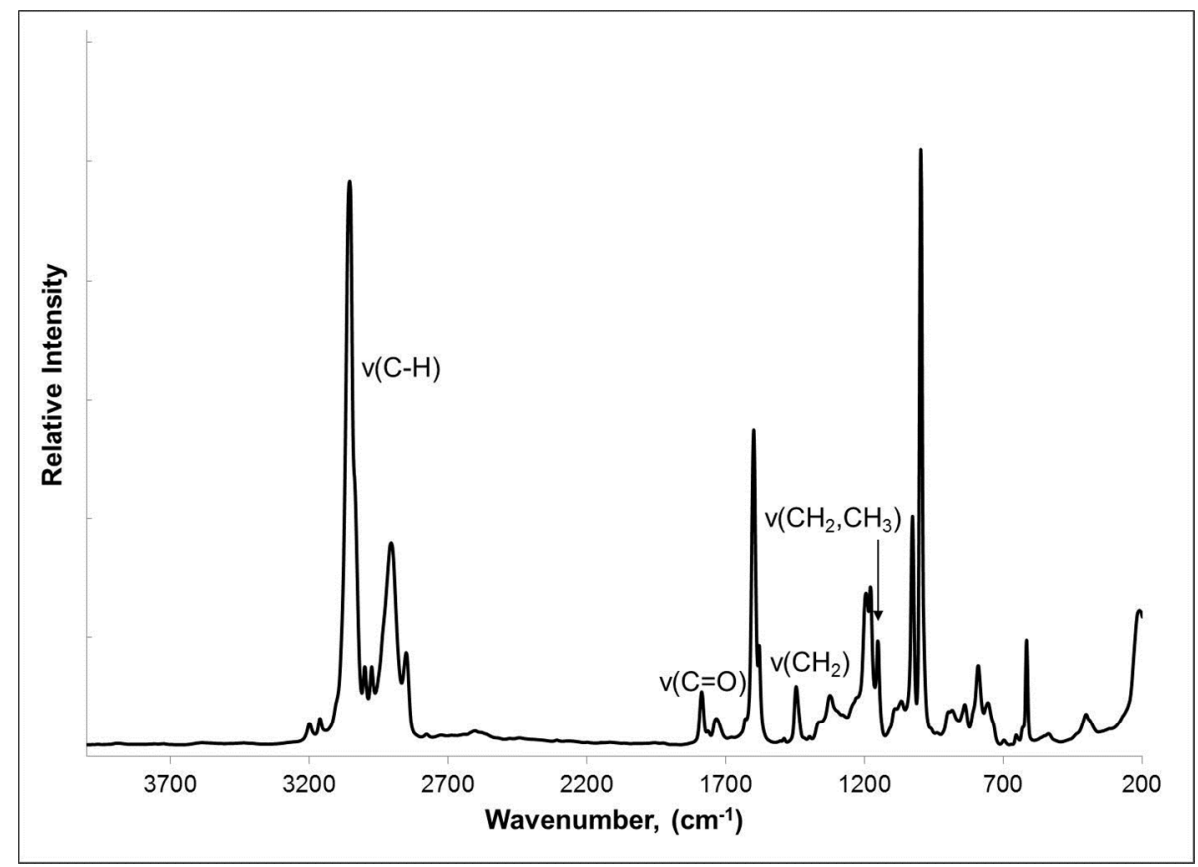

Figure S12. Raman spectra of BPO beads after removal from DMA wafer following contact tests. Signals from PMA are in good agreement with those from the PMA spectrum in Fig. S10. 


\section{Contact-initiated polymerization test with functionalized beads}

The inhibitor was removed from MA before polymerization by passage through basic alumina. BPO particles $(6 \mathrm{mg})$ and DMA particles $(6 \mathrm{mg})$ were added to a weighing bottle and mixed with a spatula. A volume of $0.2 \mathrm{~mL}$ of MA was added on top of the particles. The lid was placed on top of the weighing bottle and aluminum foil was used to cover the setup. For the quiescent experiments, the beads were left to sit in stationary contact (without a weight). For the agitated experiments, the beads and monomer were stirred with a magnetic stir bar. The reaction was allowed to occur for 90 minutes at room temperature in all experiments. Following the reaction, excess MA was removed by pipette and the beads were washed with Milli-Q water and methanol to remove unreacted MA monomer. The beads were dried under ambient atmosphere and removed from the weigh bottle for analysis.

We note that other concentrations of DMA and BPO particles (2:1 and 1:2) also resulted in 'clot' formation in the quiescent state. Thus, the ratio of the two particles does not necessarily need to be matched to achieve initiation and polymerization.

Four control experiments were conducted, two with BPO and carboxy-PS beads and two with DMA and carboxy-PS beads. A quiescent and agitation experiment was conducted for each pair (Table S1).

Table S1. Contact tests with functionalized beads.

\begin{tabular}{|c|c|c|c|}
\hline Experiment number & Bead 1 & Bead 2 & Contact type \\
\hline i & BPO & DMA & quiescent \\
\hline ii & BPO & carboxy-PS & quiescent \\
\hline iii & DMA & carboxy-PS & quiescent \\
\hline iv & BPO & DMA & agitated \\
\hline v & BPO & carboxy-PS & agitated \\
\hline vi & DMA & carboxy-PS & agitated \\
\hline
\end{tabular}

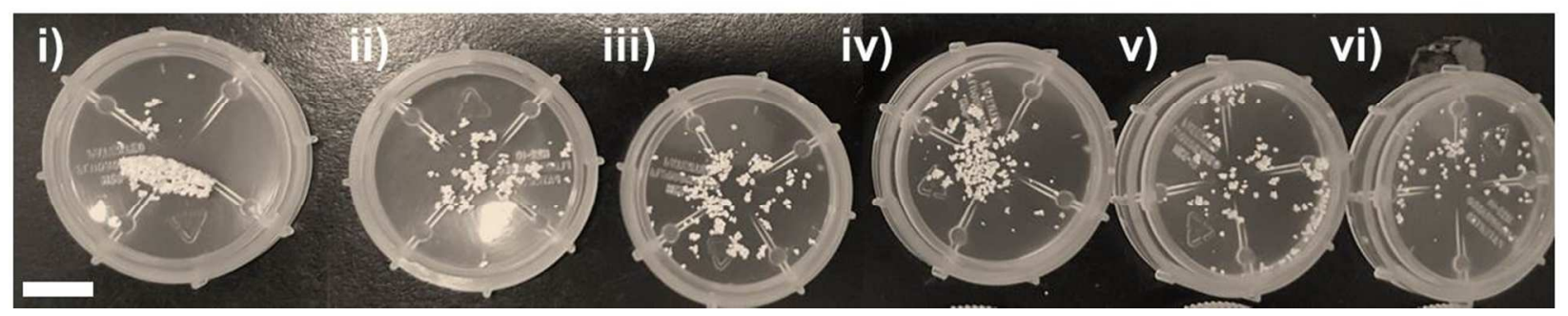

Figure S13. Photograph of beads after contact tests. Labels correspond to experiments listed in Table S1. Scale bar is $1000 \mu \mathrm{m}$. Stereo microscope images provided in main text. 
IX. Confocal Raman images and spectra of functionalized beads
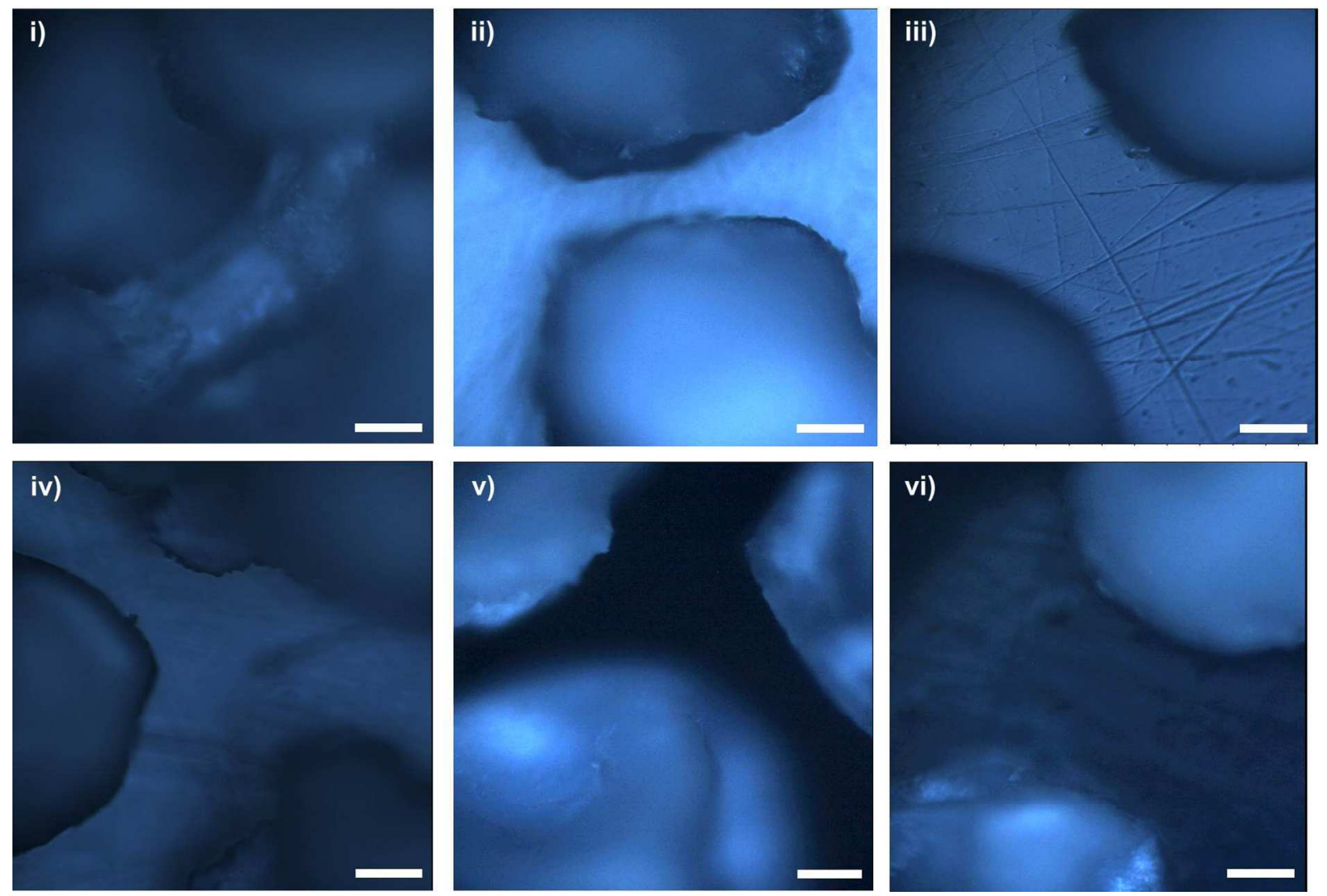

Figure S14. Confocal Raman images of beads following contact tests. Experiment numbers listed in Table S1. Only experiment (i) (BPO-DMA quiescent beads) are held together. Scale bar is $10 \mu \mathrm{m}$. 


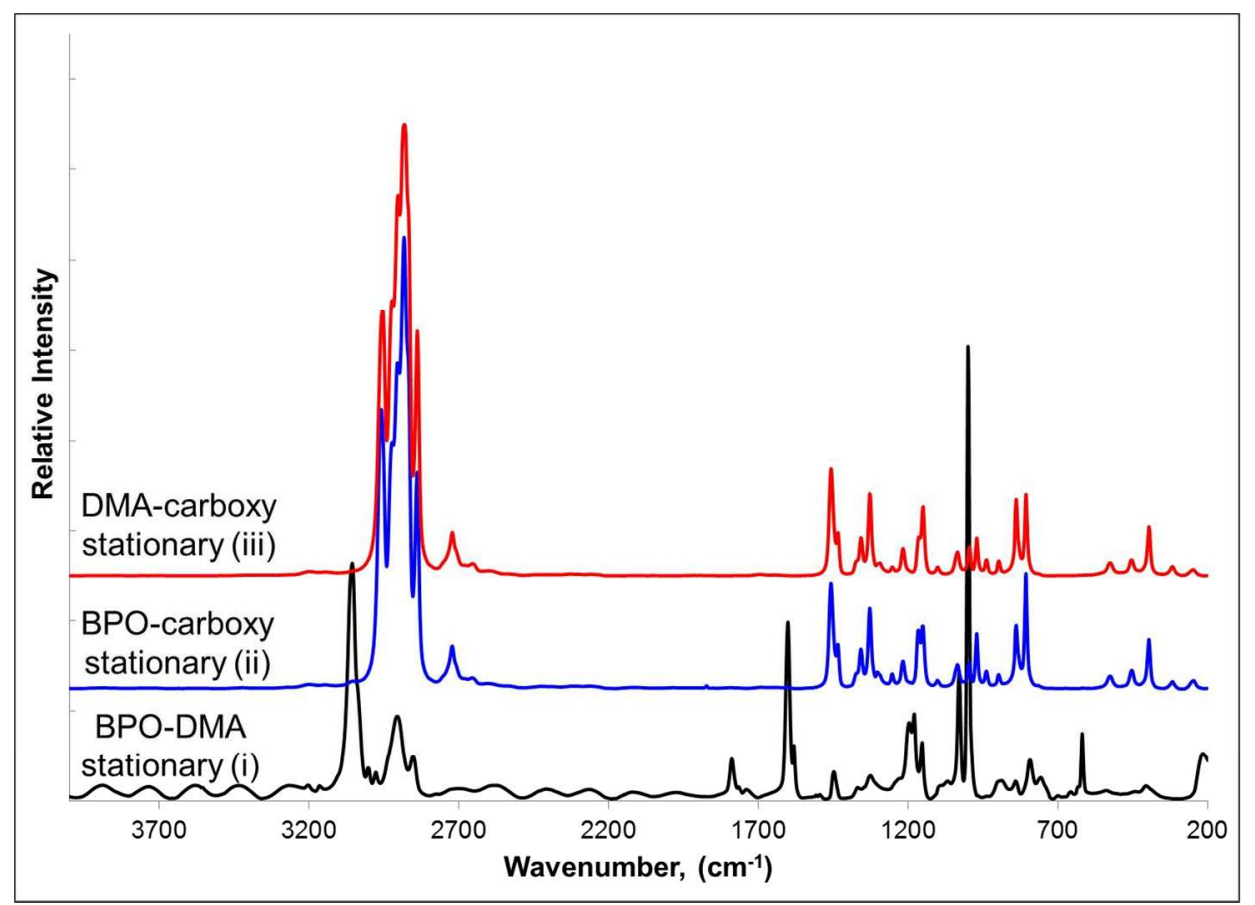

Figure S15. Raman spectra of beads following quiescent contact tests: BPO-DMA, BPOcarboxy-PS, and DMA-carboxy-PS. Only BPO-DMA exhibits signals from PMA.

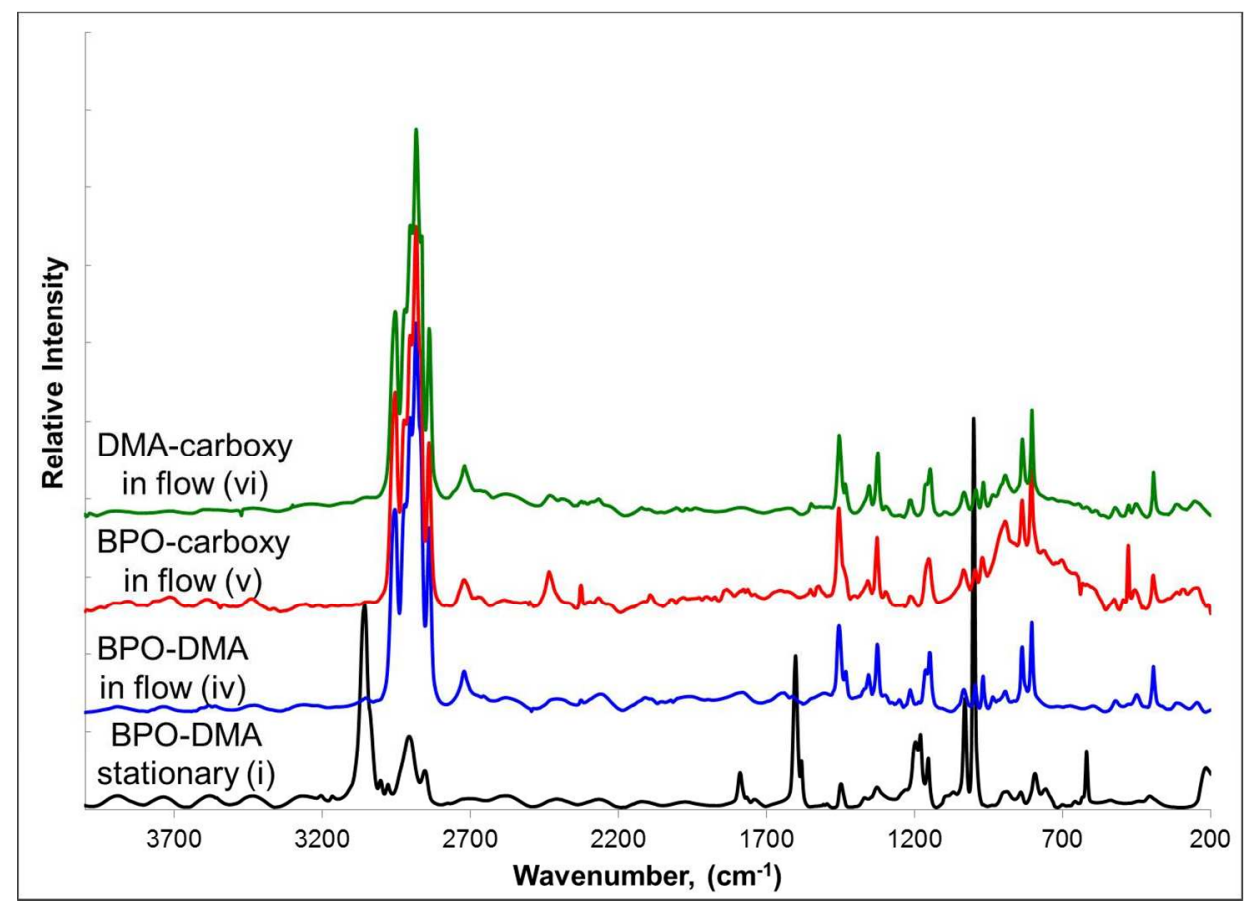

Figure S16. Raman spectra of beads following agitation contact tests: BPO-DMA, BPOcarboxy-PS, and DMA-carboxy-PS. BPO-DMA quiescent experiment is shown for comparison. 


\section{SEM images of polymer beads}

a)

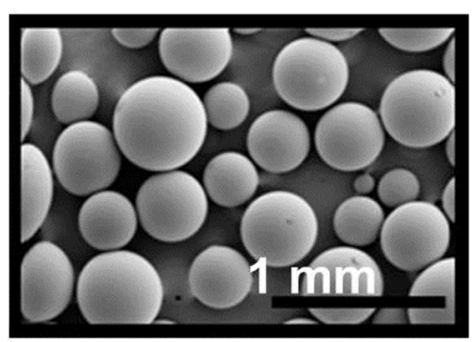

c)

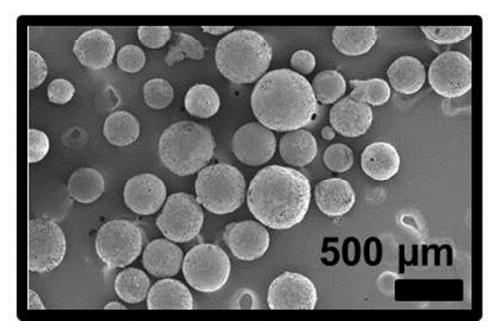

b)

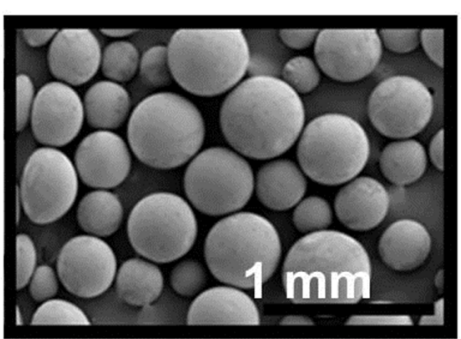

d)

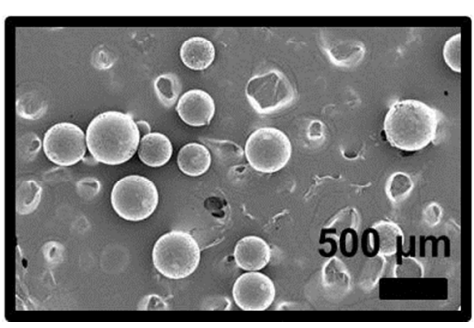

Figure S17. SEM images of: a) protected carboxy-PS beads, b) deprotected carboxy-PS beads, c) BPO functionalized beads, and d) DMA-functionalized beads.

a)
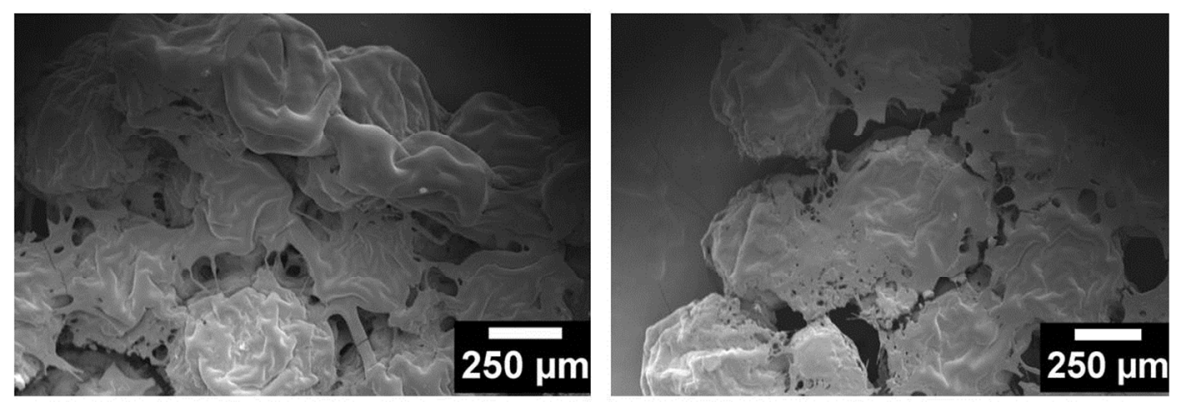

b)
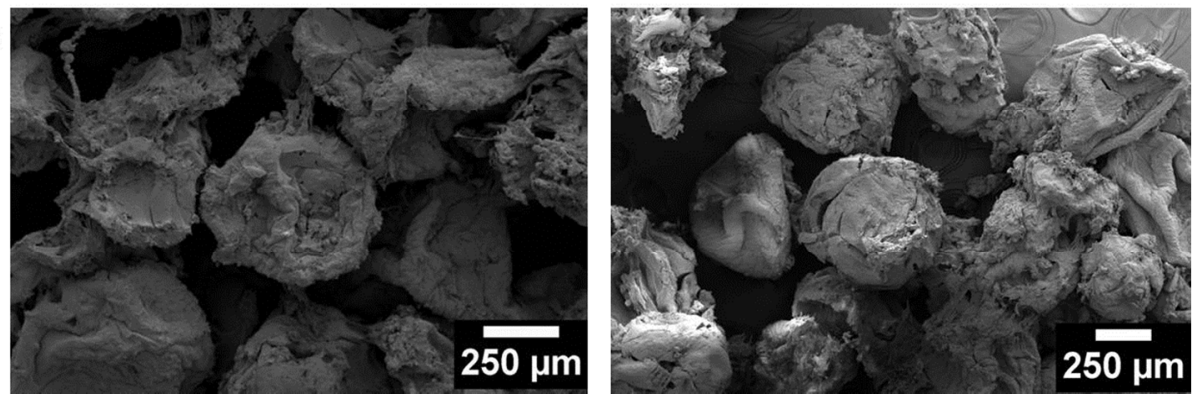

Figure S18. SEM images of: a) BPO beads after contact test with DMA surface and b) BPO and DMA beads after quiescent contact test. 


\section{Swelling studies with polymer beads}

Optical images of the BPO and DMA beads were taken in the dry state. The beads were swollen in neat methyl acrylate for a period of 30 minutes. The diameters of the particles were measured before and after swelling. The beads were removed from methyl acrylate for the swollen measurements. A total of five BPO and DMA particles were swollen and the average values are reported below.

Table S2. Swelling experiments in methyl acrylate.

\begin{tabular}{|c|c|c|c|c|c|}
\hline Bead type & $\begin{array}{c}\text { Dry } \\
\text { diameter } \\
(\mu \mathrm{m})\end{array}$ & $\begin{array}{c}\text { Swollen } \\
\text { diameter } \\
(\mu \mathrm{m})\end{array}$ & $\begin{array}{l}\text { Increase in } \\
\text { diameter } \\
(\mu \mathrm{m})\end{array}$ & $\begin{array}{c}\text { Increase in } \\
\text { size (\%) }\end{array}$ & Volume ratio \\
\hline \multicolumn{6}{|l|}{ BPO } \\
\hline 1 & 548.5 & 621.0 & 72.5 & 13.2 & 1.5 \\
\hline 2 & 496.4 & 552.2 & 55.8 & 11.2 & 1.4 \\
\hline 3 & 756.9 & 786.6 & 29.7 & 3.9 & 1.1 \\
\hline 4 & 428.9 & 470.5 & 41.6 & 9.7 & 1.3 \\
\hline 5 & 595.2 & 695.1 & 99.9 & 16.8 & 1.6 \\
\hline BPO Average & 565.2 & 625.1 & 59.9 & 11.0 & $1.4 \pm 0.2$ \\
\hline \multicolumn{6}{|l|}{ DMA } \\
\hline 1 & 754.7 & 878.3 & 123.6 & 16.4 & 1.6 \\
\hline 2 & 853.4 & 1049.0 & 195.6 & 22.9 & 1.9 \\
\hline 3 & 621.5 & 708.5 & 87.0 & 14.0 & 1.5 \\
\hline 4 & 654.0 & 695.1 & 41.1 & 6.3 & 1.2 \\
\hline 5 & 565.3 & 695.0 & 129.7 & 22.9 & 1.9 \\
\hline DMA Average & 689.8 & 805.2 & 115.4 & 16.5 & $1.6 \pm 0.3$ \\
\hline
\end{tabular}

${ }^{a}$ The volume ratio is equal to the cube of the swollen particle diameter divided by the cube of the dry particle diameter.

a)

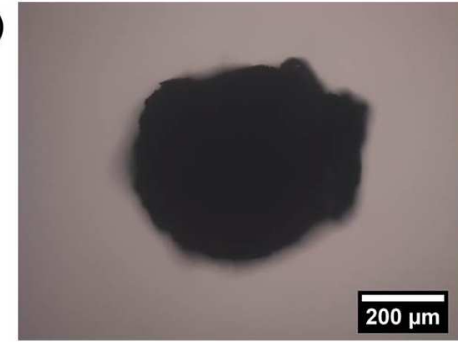

c)

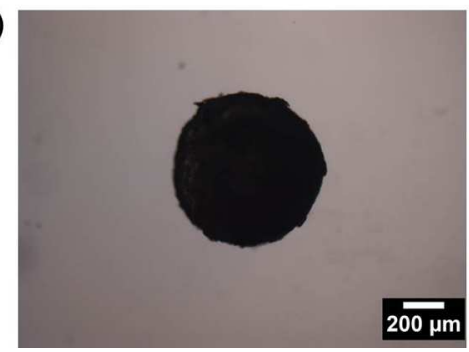

b)

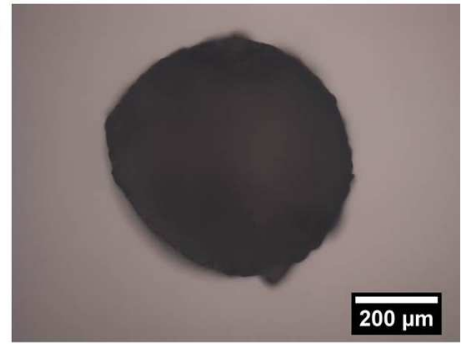

d)

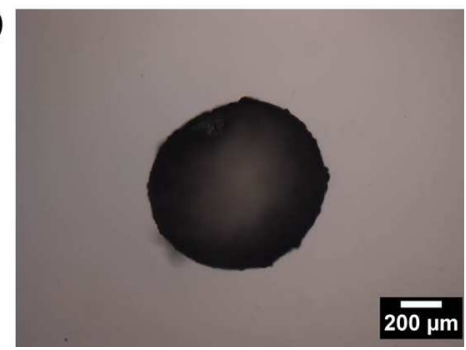

Figure S19. Optical images of: BPO beads (number 1 from table) (a) dry and (b) swollen, and DMA beads (number 1 from table) (c) dry and (d) swollen. 


\section{References}

(1) Smith, A. B.; Risatti, C. A.; Atasoylu, O.; Bennett, C. S.; Liu, J.; Cheng, H.; TenDyke, K.; Xu, Q. J. Am. Chem. Soc. 2011, 133, 14042.

(2) Wiles, C.; Watts, P.; Haswell, S. J. Tetrahedron Lett. 2006, 47, 5261.

(3) Li, Z. F.; Ruckenstein, E. Macromolecules 2002, 35, 9506. 